\title{
Probabilistic analysis of groundwater-related risks at subsurface excavation sites
}

\author{
A. Jurado ${ }^{\text {a,b,* }}$, F. De Gaspari a,b ${ }^{\text {, }}$ V. Vilarrasa ${ }^{\text {a,b }}$, D. Bolster ${ }^{\text {b,c }}$, X. Sánchez-Vila ${ }^{\text {, }}$, \\ D. Fernàndez-Garcia ${ }^{\text {b }}$, D.M. Tartakovsky ${ }^{\mathrm{d}, 1}$ \\ a GHS, Institute of Environmental Assessment E Water Research (IDAEA), CSIC, Jordi Girona 18-26, 08034, Barcelona, Spain \\ b GHS, Dept Geotechnical Engineering and Geosciences, Universitat Politècnica de Catalunya, UPC-Barcelona Tech, Jordi Girona 1-3, 08034, Barcelona, Spain \\ c Department of Civil Engineering and Geological Sciences, University of Notre Dame, Indiana, USA \\ d Department of Mechanical and Aerospace Engineering, University of California, San Diego, La Jolla, USA
}

\section{A R T I C L E I N F O}

\section{Article history:}

Received 30 June 2011

Received in revised form 21 October 2011

Accepted 22 October 2011

Available online 4 November 2011

\section{Keywords:}

Risk assessment

Fault tree analysis

Underground construction

Unforeseen events

\begin{abstract}
A B S T R A C T
Construction of underground structures (e.g., subway lines, railways and highway tunnels) is inherently hazardous, posing risks to both workers and machinery at the site and to surrounding buildings. The presence of groundwater may increase these risks. We develop a general probabilistic risk assessment (PRA) framework to quantify risks driven by groundwater to the safety of underground constructions. The proposed approach is fully compatible with standard PRA practices, employing well-developed risk analysis tools based on the fault tree analysis method. The novelty and computational challenges of the proposed approach stem from the reliance on a combination of approaches including extracting information from databases, solving stochastic differential equations, or relying on expert judgment to compute probabilities of basic events. The general framework is presented in a case study and used to estimate and minimize risks at a construction site of an underground station for a new subway line in the Barcelona metropolitan area.
\end{abstract}

(c) 2011 Elsevier B.V. All rights reserved.

\section{Introduction}

The development of an underground civil construction below the water table requires rigorous and careful planning. Groundwater is a key element in most construction projects (Forth, 2004).Water may undermine construction reliability and safety since it exerts extra loads on linings, induces mechanical instabilities, and might enhance environmental pollution from work sites. Soil heterogeneity and insufficient subsurface characterization render accurate predictions of safety and reliability elusive. Examples of soil-related failures of underground structures built below the water table include the collapse of the Seoul (South Korea) subway tunnel (Shin et al., 2006) and that of a metro station in Cologne (Germany) (Rowson, 2009), holes at the construction of the High Speed Train tunnel in Barcelona (Pujades et al., 2011) and cave-ins in a number of places including the Nicoll Highway Station (Singapore), an excavation site in Kaobsung (Taiwan) and a subway station in Shanghai (China) (Ishihara and Lee, 2008). These unforeseen events during the excavation works can lead to serious problems (de Rienzo et al., 2008),

\footnotetext{
* Corresponding author at: Jordi Girona 18, 08034 Barcelona, Spain. Tel.: + 34 934006100; fax: + 34932045904.

E-mail address: annajuradoelices@gmail.com (A. Jurado).

1 This study was originated as part of a workshop conducted by DMT at the Universitat Politècnica de Catalunya - Barcelona Tech, sponsored by the Spanish Ministry of Science. DMT's work was supported by the Office of Science of the U.S. Department of Energy, Advanced Scientific Computing Research (ASCR) program in Applied Mathematical Sciences.
}

posing at risk both workers (OSHA, 2003) and surrounding buildings (Hislop, 1999).

Given the high frequency of failures related to the ubiquitous uncertainty about subsurface environments, the existence of numerous examples on the assessment of risk of underground constructions should come as no surprise (e.g., Einstein, 1996; Sturk et al., 1996; Anderson, 1998; Seward et al., 2000; Choi et al., 2004; Eskesen et al., 2004; Ghosh and Jintanapakanont, 2004; Hong et al., 2009; Šejnoha et al., 2009; Aliahmadi et al., 2011). The abundance of cases turns out in a wide variety of methodological approaches. We focus on analyses aimed at identifying basic events contributing to the failure of a construction site and to analyze them by means of fault trees, leaving the determination of probabilities of basic events to "expert judgment", databases and stochastic differential equations. For example, the risk analysis of a tunnel excavation below the water table used empirical data from a number of underwater tunnels to identify poor ground conditions, high water pressure, and heavy rainfall as basic events contributing to tunnel failure (Hong et al., 2009). The evaluation of the probability for each accident path and its quantification was obtained by averaging the assessments of four experts.

Expert assessments of subsurface processes tend to be either deterministic or at best rely on a few Monte Carlo realizations to represent system parameter uncertainty (Tartakovsky and Winter, 2008). More rigorous uncertainty quantification efforts in hydrogeology typically rely on the variance of system states as a measure of predictive uncertainty (e.g., Rubin, 2003). Since relationships between system states and system parameters are nonlinear and often nonlocal, the 
former are expected to be highly non-Gaussian, so that knowledge of their variances is insufficient to predict probabilities of occurrence of rare events required for a probabilistic risk assessment (PRA). While a Monte Carlo approach can be used to compute a full probability density function (PDF) of the system state, it is computationally expensive and seldom used in three-dimensional transient models with a large number of cross-correlated variables. Alternative approaches based on PDF equations (Sanchez-Vila et al., 2009; Tartakovsky and Broyda, 2010) can effectively reduce this computational burden but these promising methods are still not readily available for real applications.

The use of a formal PRA framework to predict the dynamics of distributed physical systems with uncertain parameters, modeled by means of stochastic partial differential equations (SPDEs), and of which subsurface flow and transport are prime examples, offers a number of conceptual and computational advantages (Tartakovsky, 2007; Winter and Tartakovsky, 2008; Bolster et al., 2009). First, it allows one to reduce the dimensionality of the parameter space, a procedure akin to stratified Monte Carlo sampling (see Helton and Davis, 2003). Second, it treats a subsurface environment as a complex system, whose reliability and failure are reduced to those of its basic events or "components". This enables one to obtain a schematic piece-by-piece description of risks posed by the system in a way that allows for a seamless incorporation of stochastic models of subsurface processes into a global PRA framework.

The PRA approach we pursue in our analysis of risks posed by groundwater to the integrity of underground construction is based on a fault tree analysis (FTA). This approach consists of (1) defining
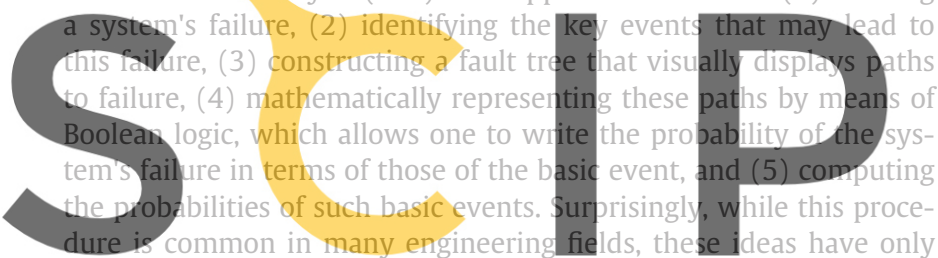

been recently introduced into analysis of groundwater related problems (Tartakovsky, 2007; Bolster et al., 2009; de Barros et al., 2011).

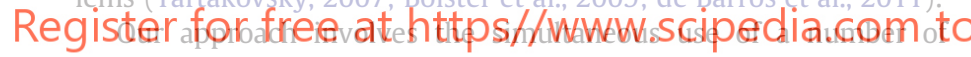

methods to compute the probability of basic events. These range from stochastic modeling and data assimilation to statistical analysis of historical data and expert judgment, the later being either of a quantitative or qualitative nature. The risk analysis is framed in an FTA, making it possible to study a complex system in a structured and straightforward manner. The specific motivation for this work comes from the construction of a new subway line in the Barcelona metropolitan area (Spain). While the methodology is general, the numbers presented here come from an example in this project.

\section{Problem formulation}

We start by considering a multilayered and isotropic subsurface environment of constant thickness (from here on we indicate in brackets the actual values used in the example, here being $b=40 \mathrm{~m}$ ) with infinite lateral extent, selected as a prospective site for an underground station. While this geologic setup is clear a simplification of reality, we contend that it is a reasonable approach when the size of the excavation is smaller than the horizontal correlation length of hydraulic conductivity and larger than the vertical one. Our goals are to quantify and minimize the risk posed by groundwater seepage during the construction of the underground station. The latter goal is important in the planning stages of the development. Risk would be controlled by the uncertainties in processes and parameters, regarding geological and hydraulic properties, but also by construction or operational conditions. The standard approach in engineering is to use representative values of parameters and to design the system incorporating a safety factor. This factor is included to account for uncertainties in the parameters, bad construction practices, and potential damages produced by unknown factors. The use of a high safety factor results in an increase in the budget.

We start by describing the main characteristics of the site that will be used as example in the risk assessment process. The hydrogeological formation consists of a shallow aquifer and a main one, separated by a silty-clayey aquitard ( $25 \mathrm{~m}$ thick) acting as a confining layer. The shallow aquifer is unconfined with a natural constant head $\left(h_{s}=2 \mathrm{~m}\right)$. The main aquifer is thus hydraulically semiconfined with a natural constant head $\left(h_{m}=-4 \mathrm{~m}\right)$ different than that of the phreatic aquifer. The flow system at the site is at steady-state conditions, with water flowing vertically downwards driven by the difference in hydraulic heads between the shallow and the main aquifers. This hydrologic system is subdivided into twelve distinct layers, whose characteristics are presented in Table 1. While this geologic setup does not correspond to any particular location, it can be considered as a representative site of the city of Barcelona.

Fig. 1 provides a vertical cross-section of the proposed construction site. A circular subway station is to be built between the shallow and main aquifer. A station construction design calls for a partially penetrating pumping well (radius $\mathrm{r}_{\mathrm{w}}=0.2 \mathrm{~m}$ ) to be placed in the center of the excavation zone, whose sides are to be aligned with a diaphragm wall (located at $r_{\text {exc }}=32 \mathrm{~m}$ ). The well is screened so that it does not exceed the bottom level of the diaphragm wall (up to $z=28 \mathrm{~m}$ below sea level, mbsl).This wall is embedded in the impervious layer. The bottom level of the diaphragm wall and the excavation level are 29 and $14.5 \mathrm{mbsl}$, respectively. The design of the pumping well included a deterministic stability assessment of the system

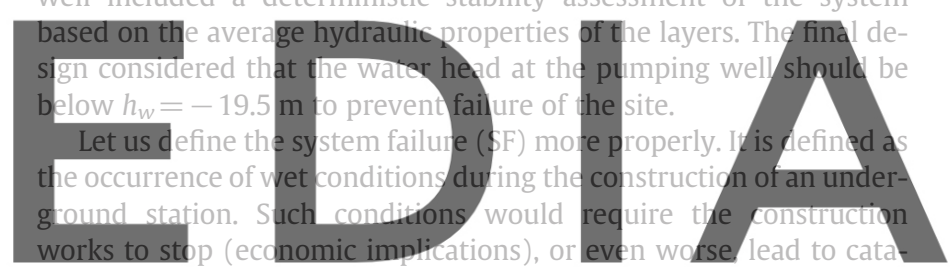
strophic failures. More specifically, we say that the system fails if the groundwater level reaches or exceeds the excavation (at level dow malo,dethe versio conbithoutt thenwaterimnark implemented following the same approach. In order to avoid system failure, the uncertainties of the events involved in our problem have to be quantified.

We focus on three main events: (1) bottom excavation failure; (2) lateral inflow, and (3) failure of the drainage system. We treat each of these sources of failure as equally undesirable, so that failure occurs when at least one of these three events take place. In subsequent analyses not carried here, weights of importance can be assigned to each event, based on either potential economic loss, or else on opinions of experts and/or decision makers, thus allowing for integration of this methodology into a decision support system.

Table 1

Description of soil layers and their properties.

\begin{tabular}{lllc}
\hline Layer & Formation & Soil type & Hydraulic conductivity (m/day) \\
\hline 1 & Shallow aquifer & Fine sand with gravel & 20 \\
2 & Shallow aquifer & Silty clay & 0.001 \\
3 & Shallow aquifer & Silty sand with gravel & 5 \\
4 & Aquitard & Silt and clay & 0.001 \\
5 & Aquitard & Sandy silt & 0.5 \\
6 & Aquitard & Silty clay with sand & 0.005 \\
7 & Aquitard & Sandy silt & 0.5 \\
8 & Aquitard & Silt and clay & 0.001 \\
9 & Aquitard & Silty clay with sand & 0.005 \\
10 & Aquitard & Sandy silt & 0.5 \\
11 & Main aquifer & Silty clay with sand & 0.025 \\
12 & Main aquifer & Gravel and sand & 150 \\
\hline
\end{tabular}




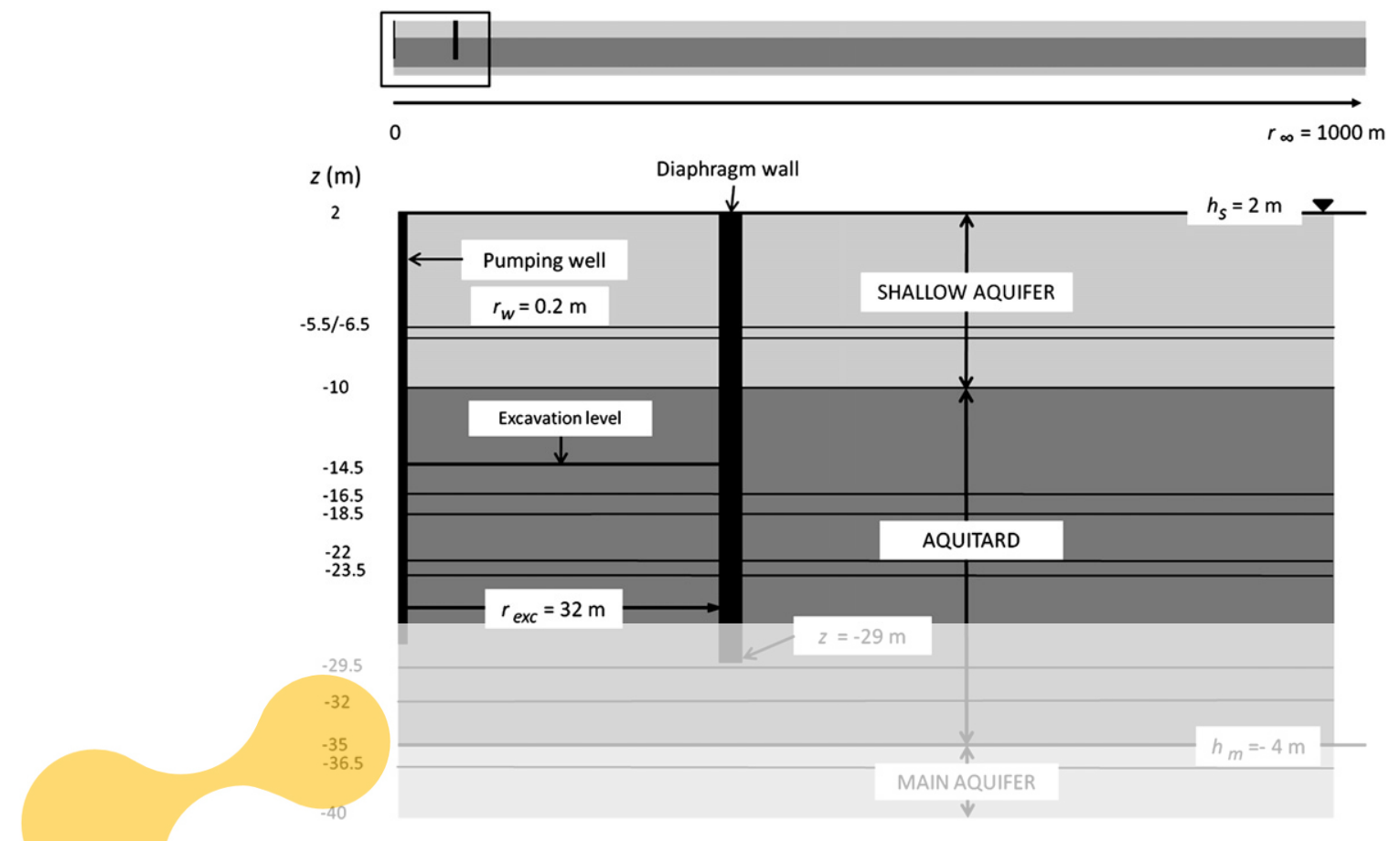

Fig. 1. Hydrogeological definition of the subsurface and schematic representation of the station construction design.
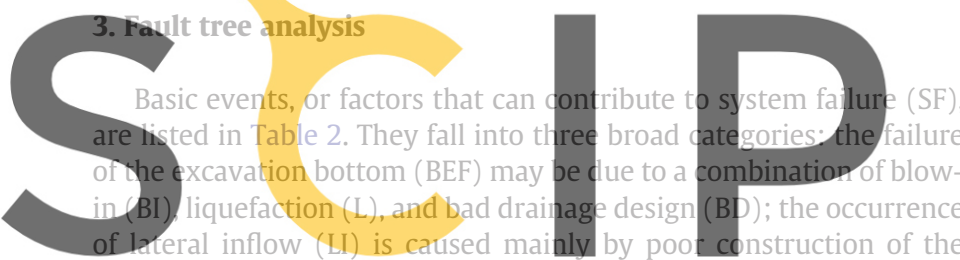

diaphragm walls; and the drainage system failure (DSF) with the subsequent flooding of the excavation site can be produced by a com-

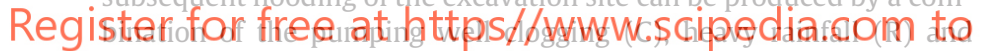
pump failure (PDW). Finally, the latter can be caused by the pump's breakdown (PB), an accidental turn-off (ATO), or a power generator failure (GF).

We use a fault tree (e.g., Bedford and Cooke, 2003) to represent the relationship between system failure (SF) and the basic events described in the previous paragraph (Fig. 2). This allows us to identify nine minimal cut sets (the smallest collection of events that lead to the system failure), each of which consisting of a single basic event: $\mathrm{BI}, \mathrm{L}, \mathrm{BD}, \mathrm{LI}, \mathrm{C}, \mathrm{R}, \mathrm{PB}, \mathrm{GF}$ and ATO. The system failure can now be represented by a Boolean equation as

$$
\mathrm{SF}=\mathrm{BEF}_{\mathrm{OR}} \mathrm{LI}_{\mathrm{OR}} \mathrm{DSF}=\left(\mathrm{BI}_{\mathrm{OR}} \mathrm{L}_{\mathrm{OR}} \mathrm{BD}\right)_{\mathrm{OR}} \mathrm{LI}_{\mathrm{OR}}\left(\mathrm{C}_{\mathrm{OR}} \mathrm{PB}_{\mathrm{OR}} \mathrm{GF}_{\mathrm{OR}} \mathrm{ATO}_{\mathrm{OR}} \mathrm{R}\right),
$$

Table 2

List of basic events.

\begin{tabular}{ll}
\hline Event & Abbreviation \\
\hline Working in wet conditions & SF \\
Bottom excavation failure & BEF \\
Blow-in & BI \\
Liquefaction & L \\
Bad drainage design & BD \\
Lateral inflow & LI \\
Drainage system fails & DSF \\
Clogging & C \\
Pump does not work & PDW \\
Rainfall & R \\
Pump breaks & PB \\
Generator fails & GF \\
Accidental turn off & ATO \\
\hline
\end{tabular}

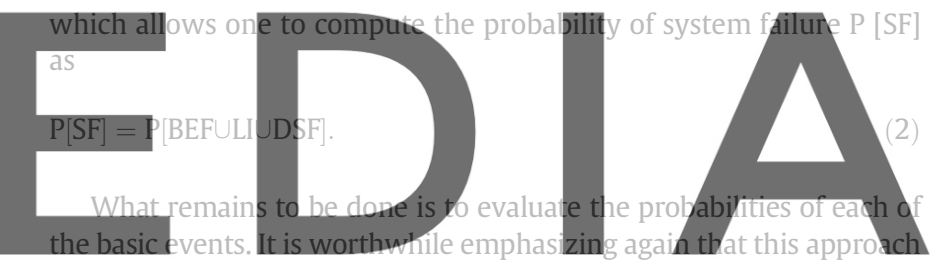

allows taking a completely different methodology to evaluate the individual components; while some of them can be found in reliability

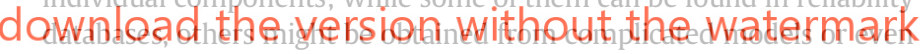
as solutions of stochastic partial differential equations.

\section{Probabilities of basic events}

The basic events leading to system failure are both natural and man-made. Consequently, the computation of the probabilities and their occurrence requires a number of distinct approaches. In the following we compute them by alternatively relying on stochastic models, recent or historic databases, and expert judgment.

\subsection{Bottom excavation failure (BEF)}

Applying the inclusion-exclusion principle of probability, we can compute $\mathrm{P}[\mathrm{BEF}]$ as

$$
\begin{aligned}
\mathrm{P}[\mathrm{BEF}]= & \mathrm{P}[\mathrm{BI} \cup \mathrm{L} \cup \mathrm{BD}]=\mathrm{P}[\mathrm{BI}]+\mathrm{P}[\mathrm{L}]+\mathrm{P}[\mathrm{BD}]-\mathrm{P}[\mathrm{BI} \cap \mathrm{L}]-\mathrm{P}[\mathrm{L} \cap \mathrm{BD}] \\
& -\mathrm{P}[\mathrm{BD} \cap \mathrm{BI}]+\mathrm{P}[\mathrm{BI} \cap \mathrm{L} \cap \mathrm{BD}] .
\end{aligned}
$$

Probabilities of the basic physical events, i.e., blow-in (BI), liquefaction (L) and a bad drainage design (BD), are computed below.

\subsubsection{Blow-in}

When the pore water pressure in a soil, $P_{w}$, exceeds the vertical total stress in the ground, the effective stress becomes zero and the soil loses its strength, forming quick sands. The consequences can be severe, causing valuable equipment to sink (Fig. 3a) and leading to personal injuries or even worker deaths. In some cases, after blow-in occurs the excavation has to be abandoned and another site 


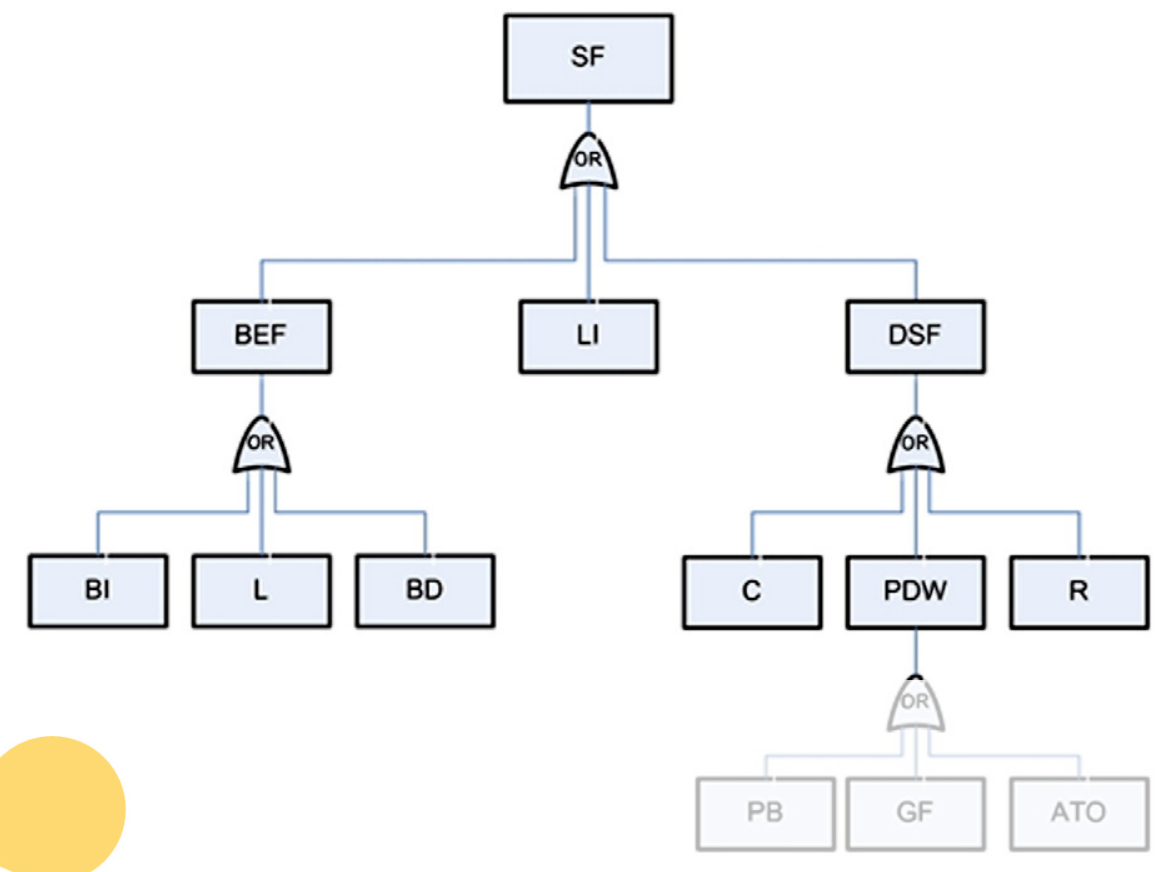

must be found, which can present severe economic consequences and

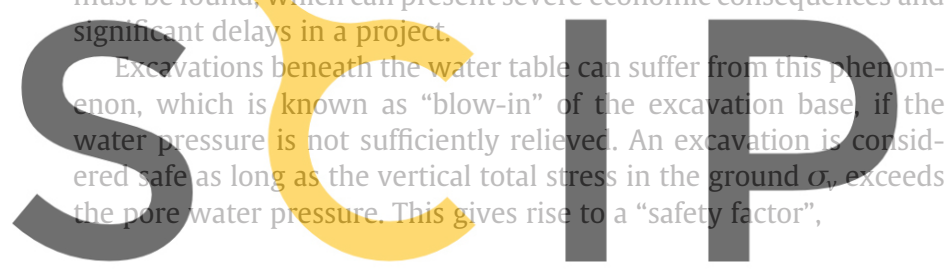

$\mathrm{FS}=\sigma_{v} / P_{w}$,

Register for free at https//www.scipedia.com to which defines the excavation to be safe if FS $>1$. In practice, it is common to require safety factors greater than 1 in order to account for the insufficient characterization of the system. The actual safety factor to be imposed in the design is chosen depending on the uncertainty associated with the site and the social and economical impact of a potential failure.

In general, blow-in is more likely to occur in silty layers that have a lower permeability compared to that of the adjacent layers since hydraulic gradients are concentrated there in. Uncertainty in the occurrence of blow-in stems from that in soil properties. We use Monte Carlo simulations to quantify this uncertainty. First, a number of equally likely realizations of permeability fields were generated by randomly assigning a value to each of the 12 layers identified in Table 1 . The permeability of each layer was treated as an independent lognormal random variable with a mean corresponding to that of the local values obtained from measurements during the geological survey of the area (Table 1), and a coefficient of variation (of the $\log -\mathrm{K}$ values) equal to 0.32 . This variance was chosen based on compiled data from the Barcelona plain area. Second, for each realization of the permeability field, flow simulations were conducted using the finite element code Transin IV (Medina and Carrera, 2003) to compute the minimum FS value that could occur at any geologic layer. Finally, the results of these flow simulations were statistically analyzed to construct the histogram of FS, which is depicted in Fig. 4a. Fig. 4b illustrates that it took approximately 3000 realizations for the Monte Carlo simulations to converge. An FS value lower or equal to 1 means that in this individual realization blow-in has occurred.
The flow simulations consider the worst flow case scenario in

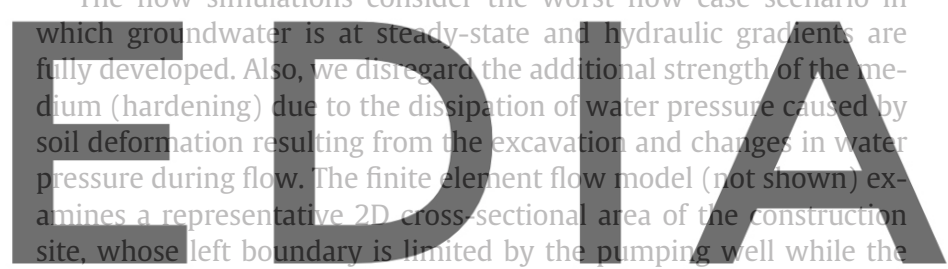
right boundary constitutes the far field. The latter avoids boundary effects by laterally extending the domain to $1000 \mathrm{~m}$. Top and bottom

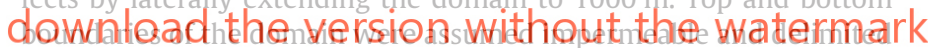
by the aquifer top/bottom boundaries. Prescribed head conditions were imposed at the pumping well and at the aquifer-bearing areas of the side boundaries, in which natural head conditions were fixed. No flow boundary conditions were prescribed elsewhere.

The Monte Carlo simulations allow us to estimate the probability of occurrence of blow-in as $\mathrm{P}[\mathrm{BI}]=0.218$, which is relatively high (see Fig. 4). Moreover, the skewed nature of the probability density function of BI implies that a deterministic study relying on averaged permeability values, which is the current "best engineering practice", would have missed the possibility of a blow-in. Another troublesome finding is that the frequency with which the safety factor FS takes values around 1 is quite large. This spike emerge naturally for the given system parameters and highlights the delicate proximity to failure by blow-in of the specific location.

\subsubsection{Liquefaction}

Liquefaction is a phenomenon with similar consequences to blowin, i.e. the occurrence of quick sands. However it is typically generated by the cyclic movements of high magnitude loads caused by earthquakes (Moh and Chin, 1993). For liquefaction to occur the soil must be susceptible to liquefaction (loose saturated sand, located close to the surface) and ground shaking must be sufficiently strong.

A number of strategies for evaluation of the liquefaction potential of a given soil are reviewed in Idriss and Boulanger (2006). In order to illustrate the potential effects of liquefaction, we consider the simplified procedure to evaluate soil liquefaction of Seed and Idriss (1971), which postulates that liquefaction at a given point occurs when the time-averaged horizontal shear stress $\tau_{a v}$ exceeds the horizontal 

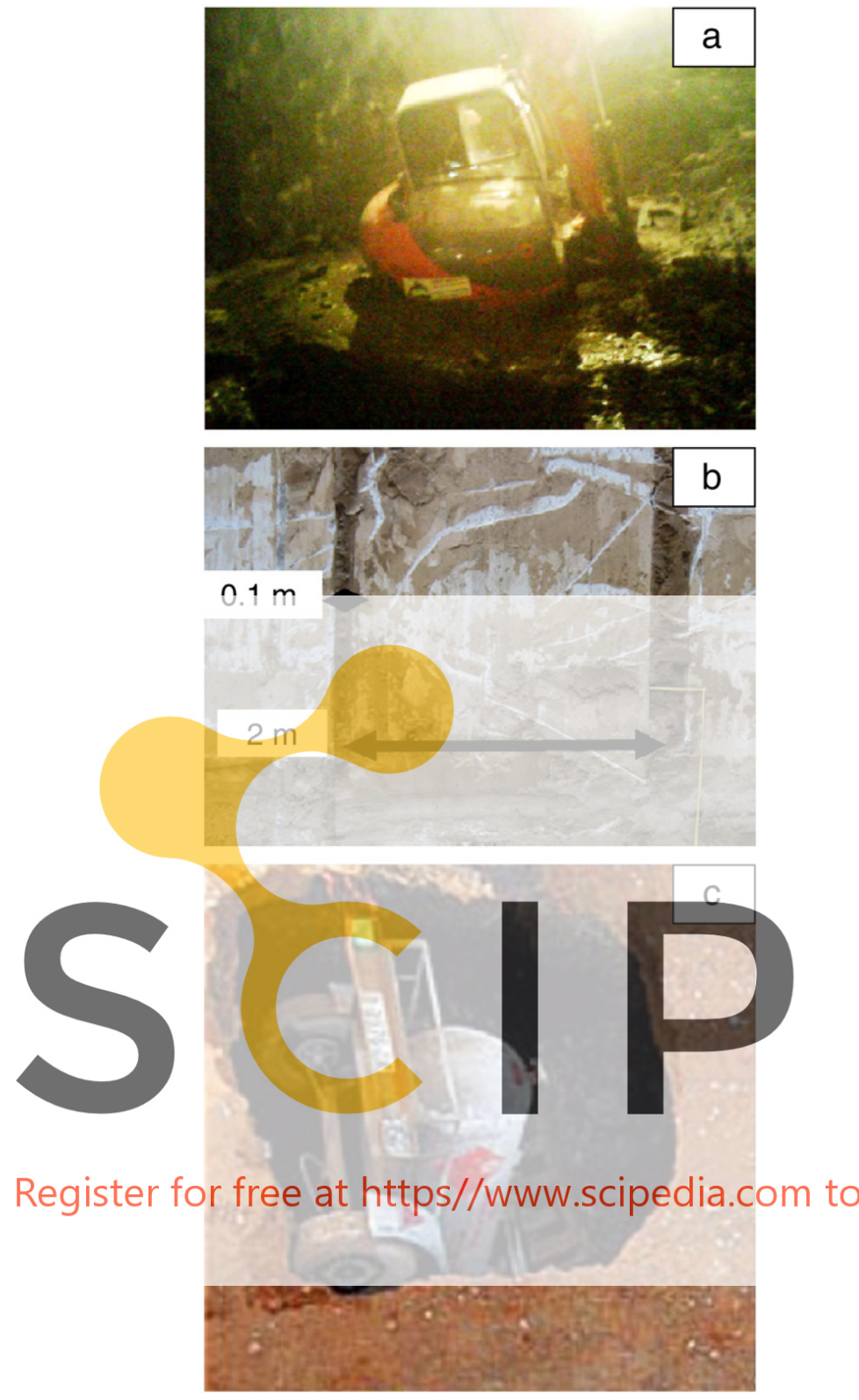

Fig. 3. Consequences of (a) blow-in phenomenon during an underground excavation, (b) open wide joints through which lateral inflow can occur, and (c) an erosion cavity.

shear stress causing liquefaction. The time-averaged shear stress is typically found to be about $65 \%$ of the maximum shear stress developed during an earthquake

$\tau_{a v}=0.65 \tau_{\max }$

which is in turn expressed in terms of the overburden total pressure $\left(\sigma_{0}\right)$ as

$\tau_{\max }=\frac{\sigma_{0}}{g} a_{\max } r_{d}$,

where $g$ is the acceleration of gravity; $r_{d}$ is a reduction coefficient that accounts for the dissipation of stresses due to soil deformation, and $a_{\max }$ is the maximum ground surface acceleration, non-linearly related to the magnitude of an earthquake $M$. The shear stress causing liquefaction $\tau_{l}$ depends on the overburden effective stress $\left(\sigma_{0}^{\prime}\right)$ given by

$\tau_{l}=R c_{r} D_{r} \sigma_{0}^{\prime}$ a
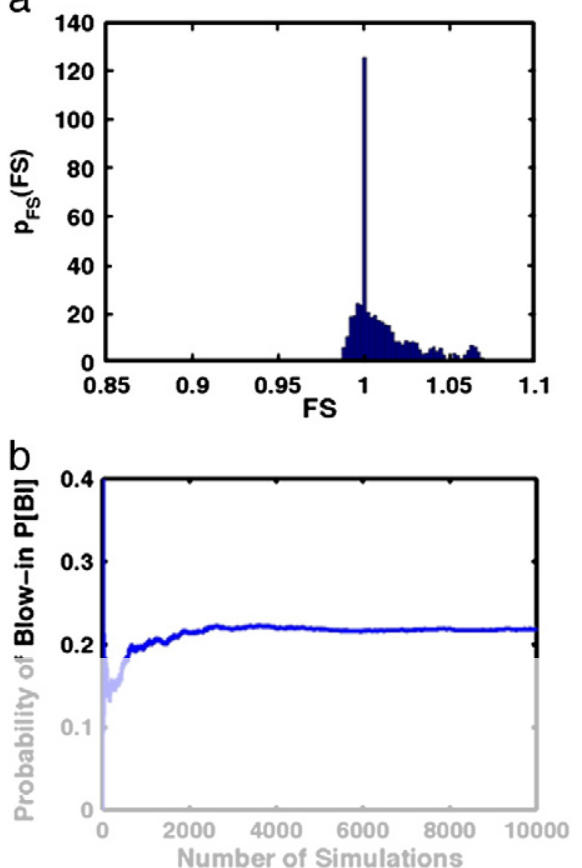

Fig. 4. (a) Histogram of the system failure due to blow in, and (b) convergence of Monte Carlo simulations with the number of realizations.

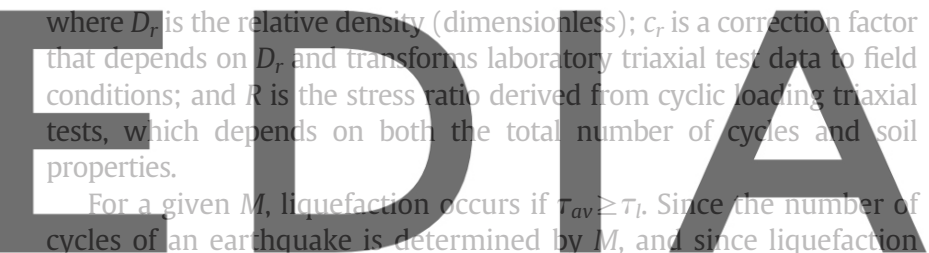

can be defined as $a_{\max }$ exceeding a given threshold, liquefaction potential can be defined as the probability that $M$ exceeds a given dawasload, theliversito, n without the watermark

$\mathrm{P}[\mathrm{L}]=\mathrm{P}\left[M>M_{0}\right]=1-\mathrm{F}\left(M_{0}\right)$

It is normally assumed that $\mathrm{F}$ follows a Gumbel distribution with parameters $\mu$ and $\beta$ (see for instance Idriss and Boulanger, 2006) so that

$F\left(M_{0} ; \mu, \beta\right)=\exp \left(-\exp \left(-\left(M_{0}-\mu\right) / \beta\right)\right)$

In Barcelona plain the following combination takes place: first, the probability of occurrence of high magnitude earthquakes is very small ( $\mu$ small), and second, the soil in Barcelona is little susceptible to liquefaction caused by cyclic loads $\left(M_{0}\right.$ large). Such a combination results in $\mathrm{F}\left(M_{0}\right)$ being very close to 1 regardless the choice of $\beta$. Thus, we set $\mathrm{P}[\mathrm{L}]=0$, but in a general problem the impact of earthquakes or, for that matter, other types of natural disasters (floods, hurricanes, landslides, volcanoes, ...) ought to be considered. It is worth noting that the proposed model is a relatively simple one. For this reason we found no need in evaluating the liquefaction potential of the soil, which would involve a number of geotechnical tests. Should the probability of liquefaction turn out to be high with the current simplified model, one could then consider running the cyclic loading triaxial tests or even using a more sophisticated modeling approach that will provide a more rigorous result. This is in fact one of the appealing features of a fault tree analysis since it is easy to recalculate the probability associated with each event without having to recalculate probabilities for the entire complex system. 


\subsubsection{Bad drainage design}

The drainage system should be designed to ensure that the water table remains at least one meter below the excavation level during the excavation. We use Monte Carlo simulations (see the numerical setup described in Section 4.1.1) to compute the probability of the water table rising above this limit. Particular attention is paid to the zones adjacent to the diaphragm wall, because they are the most unfavorable zones (located furthest from the pumping well). The standard engineering practice during the design stages is to use the average permeabilities of each layer, and to treat these values as certain. In reality though, these permeabilities are variable and highly uncertain.

Uncertainty in permeability values renders predictions of groundwater heads. Fig. 5 exhibits the normalized histogram of the relative water level computed with Monte Carlo simulations. Results are presented as differences between computed head and target level, thus a negative value indicates that the water table is more than $1 \mathrm{~m}$ below the excavation level. The bulk of realizations lie in the safe zone, but a fraction of them result in a positive value, which is indicative of failure. From the ensemble of simulations the probability of system failure due to a bad drainage design is $\mathrm{P}[\mathrm{BD}]=0.228$.

Monte Carlo simulations of blow-in in the presence of a poorly designed drain yield the probability of system failure due to the simultaneous occurrence of both blow-in and a bad drainage design being $\mathrm{P}[\mathrm{BI} \cap \mathrm{BD}]=0.011$. This probability is relatively small compared to the probability of the individual events, which suggests that they are fairly mutually excluding and that the rare event approximation (Bedford and Cooke, 2003) of Eq. (3) might be appropriate. Since

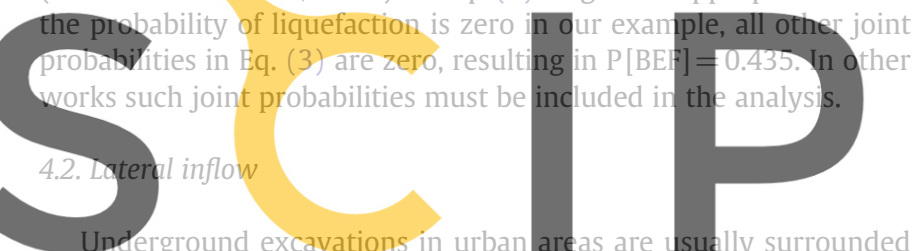
by retaining walls. These walls support the terrain outside the excavation, so that (1) the area affected by the excavation is minimized,

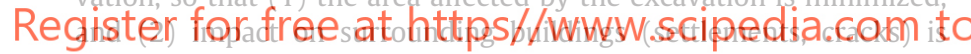

also minimized. Various types of materials for retaining walls exist. However, none of these methods provide an entirely continuous impermeable medium and joints will exist. If these joints are not closed and openings exist (Fig. 3b), groundwater will flow through, causing wet working conditions and thus leading to system failure. Additionally, open joints may lead to soil collapse and to formation of sinkholes (Fig. 3c) (Shin et al., 2006).

The Barcelona urban area is home to a large number of current and completed underground civil projects. Many previously used pumping wells have been closed, which caused the water table to rise, in some places reaching the levels of the existing underground constructions and inducing significant lateral inflow through the retaining walls (Vázquez-Suñé et al., 2004).

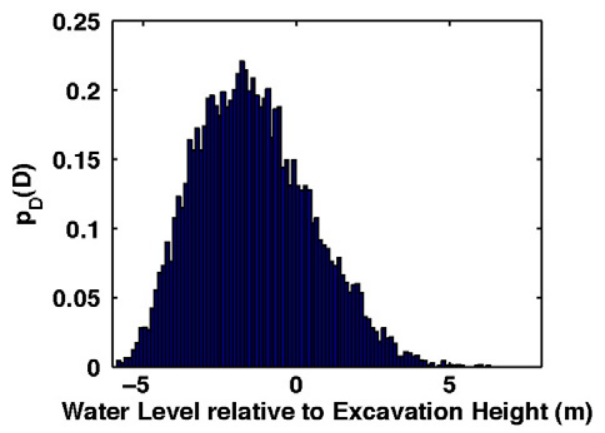

Fig. 5. Histogram of the system failure due to bad drainage design.
The probability of the occurrence of lateral inflow is particularly difficult to quantify, since it depends on the materials and technologies used at a particular construction site, regional conditions and construction standards. Thus, we rely on a literature review and existing databases to estimate P [LI]. One drawback of literature reviews associated with civil works is that sites that have suffered difficulties are more likely to be documented than those that have not presented problems. This drawback is not an issue in this case, because of our access to raw data in the study region (Vázquez-Suñé et al., 2004; Jurado et al., 2009; Vilarrasa et al., 2011; Font-Capó et al., 2011; Pujades et al., 2011). Based on the information about the civil works that have been conducted in the Llobregat Delta over the last ten years, we estimate the probability that lateral inflow results in the system failure as $\mathrm{P}[\mathrm{LI}]=0.1$.

\subsection{Drainage system failure}

The drainage system failure (DSF) can be caused by clogging of the well ( $C$ ), heavy rainfall ( $R$ ), or by the nump stopning (PDWI) (Fig. 2). It follows from Eq. (1) that

\section{$\mathrm{P}[\mathrm{DSF}]=\mathrm{P}[\mathrm{C} \cup \mathrm{R} \cup \mathrm{PDW}]=\mathrm{P}[\mathrm{C}]+\mathrm{P}[\mathrm{R}]+\mathrm{P}[\mathrm{PDW}]-\mathrm{P}[\mathrm{C} \cap \mathrm{R}]-\mathrm{P}[\mathrm{R} \cap \mathrm{PDW}]$ $-\mathrm{P}[\mathrm{PDW} \cap \mathrm{C}]+\mathrm{P}[\mathrm{C} \cap \mathrm{R} \cap \mathrm{PDW}]$}

Probabilities of the basic events, clogging, rain and pump failure, are computed below.

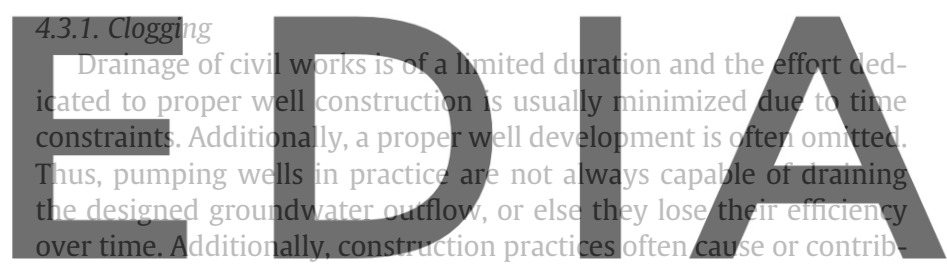

ute to well failure.

The probability of well failure on a given day changes with time. dously load the versiony Withaut tha dwatermark badly developed. Each of these construction steps might fail, leading to a well that is not able to extract the designed amount of water. Since the well is usually put into operation before the actual construction takes place, it is usually possible to correct these problems by either constructing a new well or redeveloping the existing one. In short, we can consider that the well is fully functioning at the beginning of site excavation. But, when a well is pumping for long periods of time, the drag of fine materials into the well screen may cause clogging. Consequently, the probability of clogging increases with time. This time-dependent probability is related to: (1) aquifer lithology, and (2) time that the well has been pumping. Therefore, it is helpful to have information of a specific site.

Based on the data collected from a large number of construction projects in the Barcelona area (Vázquez-Suñé et al., 2004; Jurado et al., 2009; Vilarrasa et al., 2011; Font-Capó et al., 2011; Pujades et al., 2011), we estimate the probability of clogging as $\mathrm{P}$ $[C]=0.186$.

\subsubsection{Rain}

A heavy rainfall event might cause the system to fail provided that the drainage system is not sufficient to evacuate the corresponding amount of rain water. The likelihood of a heavy rainfall is determined by local meteorological conditions, as inferred from local/regional meteorological stations. A proper drainage design consists of a number of elements diverting water from the site and additional elements that conduct water to an evacuation element, including a pumping device that takes away the water into a surface water body or a seepage system. 
We define failure caused by rainfall as the system's inability, in any single day, to avoid the accumulation of water at the site. A meteorological station located in Barcelona near the construction site used as an example in this study provides a 30 year daily data set. During this period, two heavy storms (defined as precipitation in excess of $100 \mathrm{~mm}$ in $24 \mathrm{~h}$ ) were reported. The cutoff of $100 \mathrm{~mm}$ comes from expert judgment and experience. This translates into a very small probability for an individual rain event IRE to cause the system failure, $P[I R E]=1.83 \cdot 10^{-4}$. But in areas of frequent heavy rains, this event may be significant and should be taken into account in order to estimate the added costs of taking protective approaches against (Yang et al., 2009).

Let $m$ denote the total duration of the works until the system is stabilized, or just until rain is no more an issue. Assuming that the site can be affected by rain during these $m$ days, and assuming for the sake of simplicity that daily precipitation is an independent identically distributed random variable, the probability of failure due to rain is

$\mathrm{P}[\mathrm{R}]=1-(1-\mathrm{P}[\mathrm{IRE}])^{\mathrm{m}}$

This methodology is equivalent to calculating the probability of a rain exceeding a given return period during the duration of a given construction site. The daily probability could also be considered temporally variable depending on the meteorological history of the site, provided we know the exact starting date of the construction works (e.g., accounting for summer/winter, monsoon periods, rain seasons, ), could radically change the outcome.

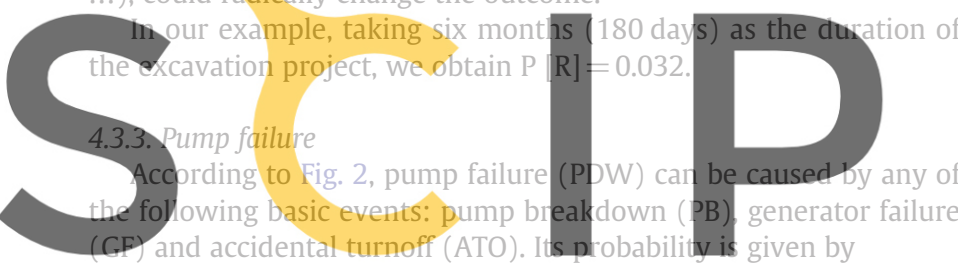

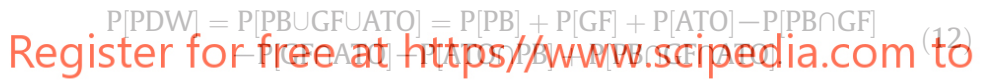

4.3.3.1. Pump breakdown (PB). The probability of pump failure, as that of many manufactured components, can be defined by an exponential cumulative distribution function over the lifetime of a pump, $\mathrm{F}_{X}(\mathrm{t}) \equiv \mathrm{P}$ $[X \leq t]=1-\exp \left(-\lambda_{p} t\right)$. This expression can be read as, the probability that a pump with a lifetime $X$ fails before time $t$ (Bedford and Cooke, 2003).

The expected or average life of the pump, $1 / \lambda_{p}$, can be evaluated from the manufacturer specifications. In practice, the intense and demanding usage of pumps in civil works reduces this ideal average life. Bad construction of wells is very common, resulting in fine particles entering the pump. These working conditions can cause pumps to break down quite frequently. In Barcelona it has been computed that pumps fail on the order of once every eighteen months. As a result of experience to avoid breakdown, pump maintenance is conducted about once every three months. Therefore, we take the mean lifetime of the pump as 18 months and the maximum probability of failure occurring at 3 months. This is equivalent to assuming that maintenance restores the pump to ideal initial operating conditions (see the discussion in Bolster and Tartakovsky, 2008), effectively setting time to $\mathrm{t}=0$ in $\mathrm{Fx}(\mathrm{t})$. While optimistic this assumption is in line with observations and experience. This results in $\mathrm{P}[\mathrm{PB}]=1-\exp$ $(-1 / 6)=0.15$, which is quite high, suggesting that better design or more frequent maintenance may be justifiable.

4.3.3.2. Generator failure (GF). In practice the drainage system must be running the whole day. The drainage system is powered by electricity from generators that use fuel. The generator can stop due to running out of fuel or a mechanical breakdown. In many conditions this does not pose a problem as a breakdown can be quickly and easily remedied. However, not all civil works have a $24 / 7$ presence at the sites. Thus, any problems that might occur with the generator during non-working hours or holidays will not be solved until the next morning, leading to system failure.

For the sake of simplicity, let us assume that the generator will always have enough fuel. Then the probability that the generator fails can be expressed by an exponential cumulative distribution function, $\mathrm{F}_{Y}(\mathrm{t}) \equiv \mathrm{P}[Y \leq \mathrm{t}]=1-\exp \left(-\lambda_{g} t\right)$. The average life of a generator, $1 / \lambda_{g}$, can be evaluated from the manufacturer specifications, and it is usually on the order of 24 months. However, in the civil work field, it is common for generators to be maintained once every two months to avoid a mechanical failure of any type. Consequently, we set $\mathrm{P}[\mathrm{PB}]=1-\exp (-1 / 12)=0.08$.

4.3.3.3. Accidental turnoff (ATO). Civil works are often conducted in tight spaces where heavy machines, construction materials, tools and workers move. Often, a machine or an object can be hit accidentally by another object. Pumping wells are placed in the center of the excavation (in order to maximize the impact of pumping) and so are susceptible to accidental bumps and damage. Based on the knowledge gained in civil works in recent years in the Barcelona area (Vázquez-Suñé et al., 2004; Jurado et al., 2009; Vilarrasa et al., 2011; Font-Capó et al., 2011; Pujades et al., 2011) we set the probability of this unlikely event to $\mathrm{P}[\mathrm{ATO}]=0.015$.
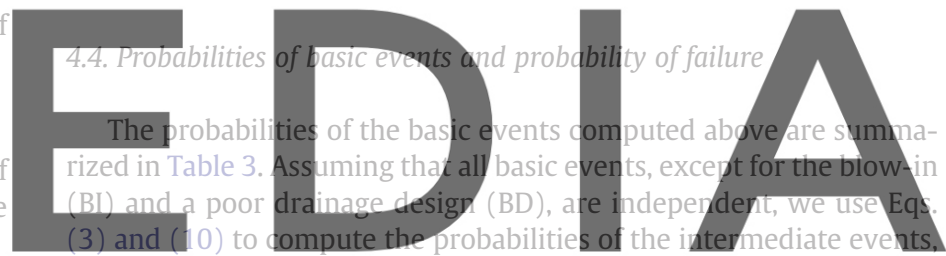

the bottom excavation failure (BEF) and the drainage system failure (DSF), respectively. These are reported in Table 3. Finally, the probadowtgload the thersionpwithaut the wsatermark which is very high. This result highlights the importance of conducting PRA to determine the likelihood of failure due to groundwater related excavation engineering problems. In this case, reliance of the "best engineering practice" is too risky.

The focus on the intermediate probabilities, $\mathrm{P}$ [BEF], $\mathrm{P}[\mathrm{LI}]$, and $\mathrm{P}$ [DSF], reveals some salient features of many underground excavation projects and provides guidance to better engineering practices. First, the high probability of the failure of the bottom of the excavation site, $\mathrm{P}[\mathrm{BEF}]=0.435$, illustrates the importance of uncertainty quantification in a stochastic analyses of groundwater flow in the soil

Table 3

Probabilities of basic and intermediate events, and probability of the system failure.

\begin{tabular}{|c|c|}
\hline Probability & Value \\
\hline $\mathrm{P}[\mathrm{BI}]$ & 0.218 \\
\hline $\mathrm{P}[\mathrm{L}]$ & 0 \\
\hline $\mathrm{P}$ [BD] & 0.228 \\
\hline $\mathrm{P}[\mathrm{BI} \cap \mathrm{BD}]$ & 0.011 \\
\hline $\mathrm{P}[\mathrm{BEF}]$ & 0.435 \\
\hline $\mathrm{P}[\mathrm{LI}]$ & 0.1 \\
\hline $\mathrm{P}[\mathrm{C}]$ & 0.186 \\
\hline $\mathrm{P}[\mathrm{PB}]$ & 0.15 \\
\hline $\mathrm{P}[\mathrm{GF}]$ & 0.08 \\
\hline P [ATO] & 0.01 \\
\hline $\mathrm{P}$ [PDW] & 0.226 \\
\hline$P[R]$ & 0.032 \\
\hline $\mathrm{P}$ [DSF] & 0.39 \\
\hline $\mathrm{P}[\mathrm{SF}]$ & 0.69 \\
\hline
\end{tabular}


adjacent to excavation sites; deterministic models employing average soil properties are likely to miss the potential danger.

Second, the probability of lateral inflow, $\mathrm{P}[\mathrm{LI}]=0.1$, is relatively low. Improving this number requires the development of better ground-improvement protocols and the implementation of stringent construction standards. These measures are likely to carry significant costs, but may well be worth the investment.

Third, the probability of drainage failure is also high, $\mathrm{P}$ [DSF] $=$ 0.39 . The events contributing to this probability are less catastrophic than those associated with $\mathrm{P}$ [BEF], although they can cause disasters if not attended quickly (e.g., Duann et al., 1997). Their consequences tend to be more economic, leading to construction delays and higher costs. Making a decision on whether to reduce these probabilities requires a cost-benefit analysis that would balance the increased costs of better equipment and a more rigorous maintenance schedule against the time and money that can potentially be lost due to failure. An example of such an analysis can be found in Bolster and Tartakovsky (2008).

We repeated the analysis described above for the case where a second pump is added to the site. We found that doing so reduces the risk of system failure to about $\mathrm{P}[\mathrm{DSF}]=0.325$. Including a third pump reduces it to around 0.16 and adding a fourth pump reduces the risk of failure to just above 0,127 , which is the minimum value that can be attained without reducing the probabilities of failure associated with lateral inflow (P [LI]) or extreme rainfall (P $[R])$. These results led to the construction managers of the subway line in Barcelona to recommend the installation of redundant pumps along the line.
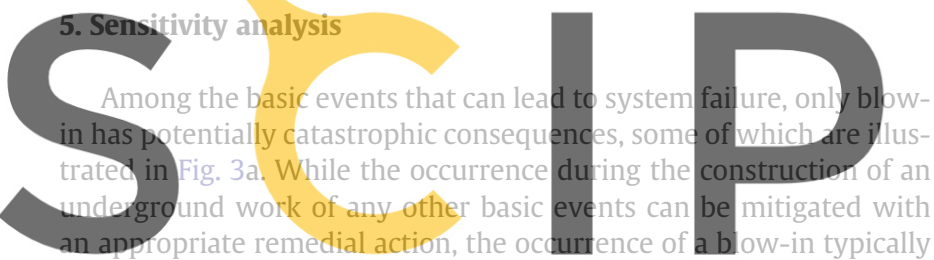
causes the complete abandonment of the construction site. This is because the soil loses its mechanical strength and ability, to bear the

Reguisteffafordfree at https//www.scipedia.com to

As mentioned before, blow-ins typically occur in low permeability layers located adjacent to permeable ones. For the site geology shown in Fig. 1, this suggests that the critical layers are either layer 4 or 8 , both located in the aquitard formation. An analysis of our Monte Carlo simulations reveals that blow-in occurs most frequently in layer 8 (L8). A sample pressure distribution corresponding to one realization where blow-in occurs, in L8 is shown in Fig. 6.

We conduct a sensitivity analysis to determine the critical permeability of L8 to blow-in. It consists of the following steps. First, the permeabilities of all the layers other than L8 are deterministically

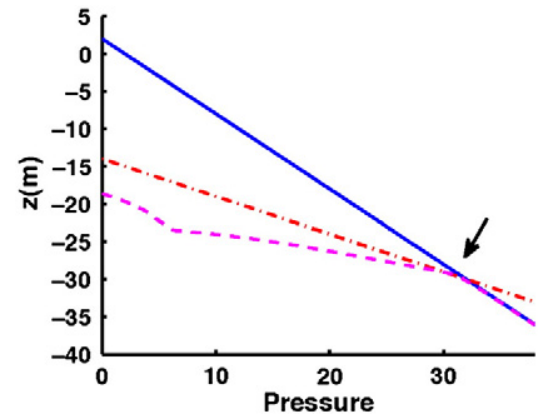

Fig. 6. Water pressure profile before (blue solid line) and after (purple dashed line) pumping at the inner face of the diaphragm wall in a realization where a blow-in occurs. The red dash-dot line shows the vertical stress due to the soil after excavation. fixed to their respective average values. Then the permeability of L8 is incrementally varied over several orders of magnitude, with values drawn from the lognormal PDF used in the Monte Carlo simulations. The results are shown in Fig. 7, which allows one to identify the log critical permeability, $\log K_{c}=-3.287$, for which the safety factor $\mathrm{FS}=1$.

To evaluate the probability of encountering the log permeability smaller than $\log K_{c}$, i.e., the probability of the system failure due to blow-in, we use the Gaussian cumulative distribution function shown in Fig. 8. For the given permeabilities in the other layers, the probability of blow-in in layer L8 is 0.172 (see Fig. 8). Comparing this probability with the original Monte Carlo simulations that yield the probability of 0.218 , we observe that layer 8 accounts for $79 \%$ of the risk of a blow-in. This suggests that it is desirable to invest extra resources into characterizing this layer.

To reduce the risk of a blow-in, the water pressure at the bottom of layer 8 should be reduced. One way of achieving this is to increase the vertical penetration of the pumping well. For example, if the pumping well were to reach layer 10 (more permeable than layer 8), pumping at this layer would reduce the water pressure at the bottom of layer 8 Alternatively, a jet-grouting treatment could be performed at the bottom and below the toe of the diaphragm wall, which would increase the mechanical strength and reduce the permeability of the soil. The depth of the jet-grouting treatment would be a new variable to account for in the risk analysis associated to blow-in.

\section{Summary and conclusions}

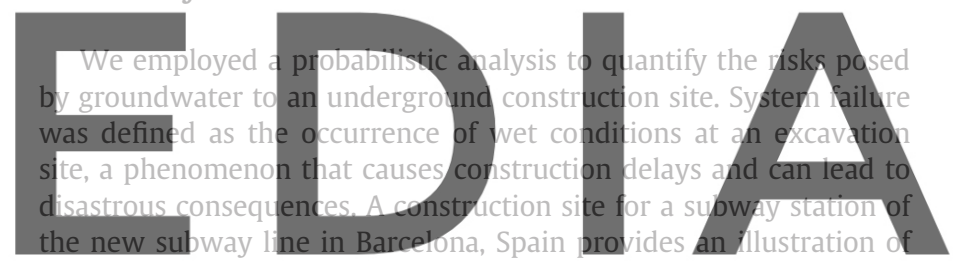

the general methodology. This site has experienced some of the adverse effects of wet conditions.

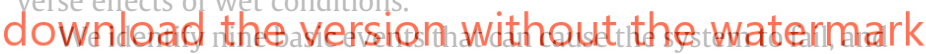 group them into three categories: (1) failure of the bottom (floor) of the excavation, which can occur by blow-in, liquefaction or a bad de-} sign of the drainage system; (2) lateral inflow, which is associated with faulty construction of the surrounding protective barriers, and (3) mechanical failure of the drainage system. These events were organized into a fault tree (Fig. 2), which allowed us to express the probability of the system failure in terms of the probabilities of basic events.

Probabilities of the basic events associated with groundwater flow (i.e., the failure of the excavation floor) cannot be inferred from reliability databases, since they are determined by a complex interplay of soil heterogeneity and construction conditions at the site. We used solutions of the stochastic groundwater flow equation in a

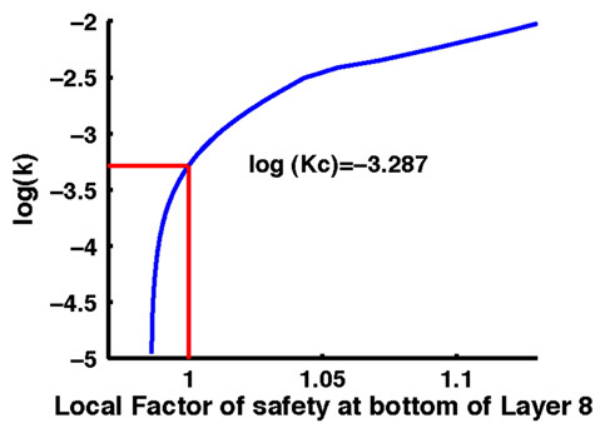

Fig. 7. Evaluation of the safety factor in the layer L8 for various permeabilities of that layer at level $29.5 \mathrm{mbsl}$ 


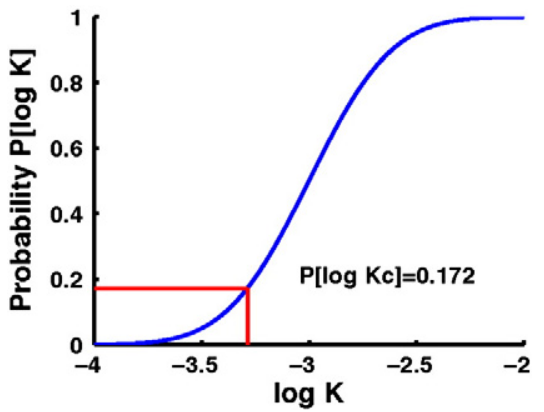

Fig. 8. The cumulative distribution function of $\log$ permeability $(\log K)$.

Monte Carlo framework to estimate these probabilities. Some basic events (e.g., the failure of the protective barrier) are so underspecified by data as to defy a physically-based quantitative description. To estimate their probabilities, we resort to expert knowledge gained from the contractors working on underground construction projects in the Barcelona area over the last decade. Finally, the probabilities of mechanical failures were estimated from the assumed life-time probability density functions and databases or manufacturer information on average lifetimes.

The estimated probability of system failure in the original design was about $70 \%$, indicating the need to perform changes in either design or operation to bring the risk down to a smaller value. Actually, a wide array of improvement strategies could be considered, ranging

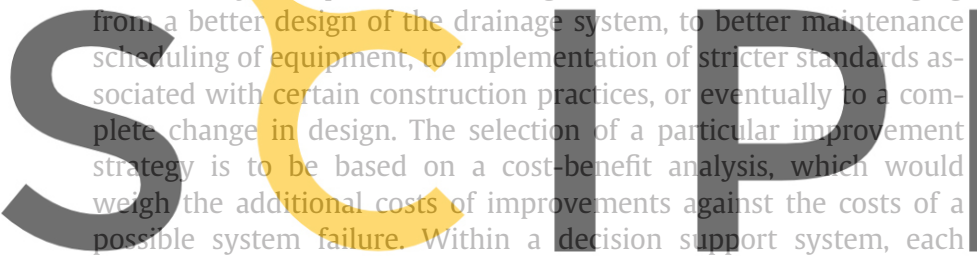
basic event can be assigned a weight in accordance with the potential impact of its outcome. For example, the consequences of a blow-in

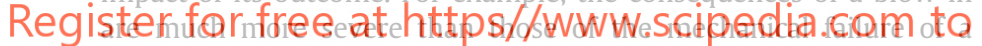
pump and should be avoided at much greater cost. The implementa tion of such a decision-support system is left for future research.

Since blow-in has the most severe consequences and its occurrence has a relatively high probability of $22 \%$, we conducted a sensitivity analysis to identify geological layers that cause most of the blow-in events in our Monte Carlo simulations. This analysis enabled us to identify several strategies for significantly reducing the risk of such an event.

One of the primary conclusions of this study is the importance of probabilistic modeling of groundwater flow at and near underground construction sites. Deterministic analyses of the specific problem presented here are likely to show that the planned excavation procedures are well designed and safe. However, this is not the case because of the ubiquitous soil heterogeneity and uncertainty about soil properties. A proper evaluation of risks should then be always considered. It is important to note that this methodology is very inexpensive, and so can be easily updated whenever new information about geology or hydraulic properties arise during the actual works.

\section{Acknowledgments}

This work was funded by PEYCO-INPASA, GISA Gestió d'Infrastructures S.A. (Generalitat de Catalunya), and the Spanish Ministry of Science and Innovation (MICINN) with projects RARAAVIS (CGL2009-11114) and HEROS (CGL2007-66748). VV and DB would like to respectively thank the funding programs of MICINN: "Formación de Profesorado Universitario" and "Juan de la Cierva".

\section{References}

Aliahmadi, A., Sadjadi, S.J., Jafari-Eskandari, M., 2011. Design a new intelligence expert decision making using game theory and fuzzy AHP to risk management in design, construction, and operation of tunnel projects (case studies: Resalat tunnel). The International Journal of Advanced Manufacturing Technology 53 (5-8), 789-798.

Anderson, J., 1998. Minimizing underground construction risks requires maximum engineering effort. Tunneling and Underground Space Technology 13, 365-368.

Bedford, T., Cooke, R., 2003. Probabilistic Risk Analysis: Foundations and Methods. Cambridge Univ. Press, Cambridge, U. K.

Bolster, D., Tartakovsky, D.M., 2008. Probabilistic risk analysis of contamination in buildings. Indoor Air 18 (5), 351-364.

Bolster, D., Barahona, M., Dentz, M., Fernandez-Garcia, D., Sanchez-Vila, X., Trinchero, P., Valhondo, C., Tartakovsky, D.M., 2009. Probabilistic risk analysis of groundwater remediation strategies. Water Resources Research 45, W06413.

Choi, H.H., Cho, H.N., Seo, J.W., 2004. Risk assessment methodology for underground construction projects. Journal of Construction Engineering and Management 130, 258-272.

de Barros, F.P.J., Bolster, D., Sanchez-Vila, X., Nowak, W., 2011. A divide and conquer approach to cope with uncertainty, human health risk, and decision making in contaminant hydrology. Water Resources Research 47, W05508.

de Rienzo, F., Oreste, P., Pelizza, S., 2008. Subsurface geological-geotechnical modeling to sustain underground civil planning. Engineering Geology 96, 187-204.

Duann, S.W., Wang, R.F., Wang, C.H., Liou, G.J., 1997. Piping Failure of a Cofferdam in Southern Taiwan, Int. Conference on Foundation Failures, Singapore, pp. 209-216.

Einstein, H.H., 1996. Risk and risk analysis in rock engineering. Tunnelling and Underground Space Technology 11 (2), 141-145.

Eskesen, S.D. Tengborg. P. Kampmann, J. Veicherts, T.H., 2004. Guidelines for tunnelling risk management: International Tunnelling Association, Working Group No. 2. Tunnelling and Underground Space Technology 24 (3), 217-237.

Font-Capó, I., Vázquez-Suñé, E., Carrera, I., Martí, D., Carbonell, R., Pérez-Estaun, A. 2011. Groundwater inflow prediction in urban tunneling with a tunnel boring machine (TBM). Engineering Geology 121, 46-54.

Forth, R.A., 2004. Groundwater and geotechnical aspects of deep excavations in Hong Koing. Engineer
Ghosh, S., Jintanapa
an undergroun
Journal of Proje
Helton, J.C., Davis,
uncertainty in
Safety 81 (1), 2
Hislop, R.D. 1999.
Press, Boca Rat
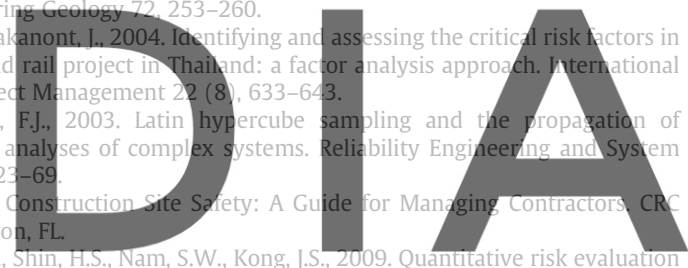
based on event tree analysis technique: application to the design of shield TBM: Tunnelling and Underground Space Technology 24 (3), 269-277. potential 1150

Ishihara, K. Lee WF 2008 Geotechnical and Geophisical Site Characterization: Forsenic Diagnosis for Site-specific Ground Conditions in Deep Excavations of Subway Constructions. Taylor \& Francis Group, London, UK.

Jurado, A., Pujades-Garnes, E., Vilarrasa, V., Vázquez-Suné, E., Carrera, J., 2009. Desarrollo de un método para resolver el drenaje de excavaciones entre pantallas. Proceedings: Jornadas sobre el Agua y las Infraestructuras en el Medio Subterráneo. AIH-GE, Barcelona, pp. 55-62.

Medina, A., Carrera, J., 2003. Geostatistical inversion of coupled problems: dealing with computational burden and different types of data. Journal of Hydrology 281 (4), 251-264.

Moh, Z.C., Chin, C.T., 1993. Recent developments in deep excavation in soft ground. Proceedings: International Conference on Geotechnical Engineering and Earthquake Resistant Technic in Soft Soil Areas, pp. 595-605.

Occupational Safety and health administration, 2003. U.S. Department of Labor, Underground Construction Tunneling, OSHA 3115-06R.

Pujades, E., Carrera, J., Vázquez-Suñé, E., Jurado, A., Vilarrasa, V., Mascuñano-Salvador, E., 2011. Hydraulic characterization of diaphragm walls for cut and cover tunnelling. Engineering Geology. doi:10.1016/j.enggeo.2011.10.012.

Rowson, J., 2009. Cologne: groundwater extraction method probed, New Civil Engineer. http://www.nce.co.uk/print-magazine/cologne-groundwater-extraction-methodprobed/ 1995535.article.

Rubin, Y., 2003. Applied Stochastic Hydrogeology. Oxford University Press, New York. Sanchez-Vila, X., Guadagnini, A., Fernàndez-Garcia, D., 2009. Conditional probability density functions of concentrations for mixing-controlled reactive transport in heterogeneous aquifers. Mathematical Geosciences 41, 323-351. doi:10.1007/s11004008-9204-2.

Seed, H.B., Idriss, I.M., 1971. Simplified procedure for evaluating soil liquefaction potential. Journal of Soil Mechanics Foundations, ASCE 97 (9), 1249-1273.

Šejnoha, J., Jarušková, D., Špačková, O., Novotná, E., 2009. Risk quantification for tunnel excavation process. Proceedings: World Academy of Science, Engineering and Technology, 58, pp. 101-109.

Seward, D., Pace, C., Morrey, R.A., 2000. Safety analysis of autonomous excavator functionality. Reliability Engrg and System Safety 70 (1), 29-39.

Shin, J.H., Lee, I.K., Lee, Y.H., 2006. Lessons from serial tunnel collapses during construction of the Seoul Subway Line 5. Tunnelling and Underground Space Technology 21 (3-4), 296-297. 
Sturk, R., Olsson, L., Johansson, J., 1996. Risk and decision analysis foe for large underground projects, as applied to the Stockholm Ring Road Tunnels. Tunelling and Underground Space Technology 11 (2), 157-164.

Tartakovsky, D.M., 2007. Probabilistic risk analysis in subsurface hydrology. Geophysical Research Letters 34, L05404.

Tartakovsky, D.M., Winter, C.L., 2008. Uncertain future of hydrogeology, ASCE. Journal of Hydrologic Engineering 13 (1), 37-39.

Tartakovsky, D.M., Broyda, S., 2010. PDF equations for advective-reactive transport in heterogeneous porous media with uncertain properties. Journal of Contaminant Hydrology. doi:10.1016/j.jconhyd.2010.08.009.

Vázquez-Suñé, E., Sánchez-Vila, X., Carrera, J., 2004. Introductory review of specific factors influencing urban groundwater, an emerging branch of hydrogeology, with reference to Barcelona, Spain. Hydrogeology Journal 13, 522-533.
Vilarrasa, V., Carrera, J., Jurado, A., Pujades, E., Vázquez-Suñé, E., 2011. A methodology for characterizing the hydraulic effectiveness of an annular low-permeability barrier. Engineering Geology 120, 68-80.

Winter, C.L., Tartakovsky, D.M., 2008. A reduced complexity model for probabilistic risk assessment of groundwater contamination. Water Resources Research 44 W06501.

Yang, F.R., Lee, C.H., Kung, W.J., Yeh, H.F., 2009. The impact of tunneling construction on the hydrogeological environment of "Tseng-Wen Reservoir Transbasin Diversion Project" in Taiwan. Engineering Geology 103 (1-2), 39-58.
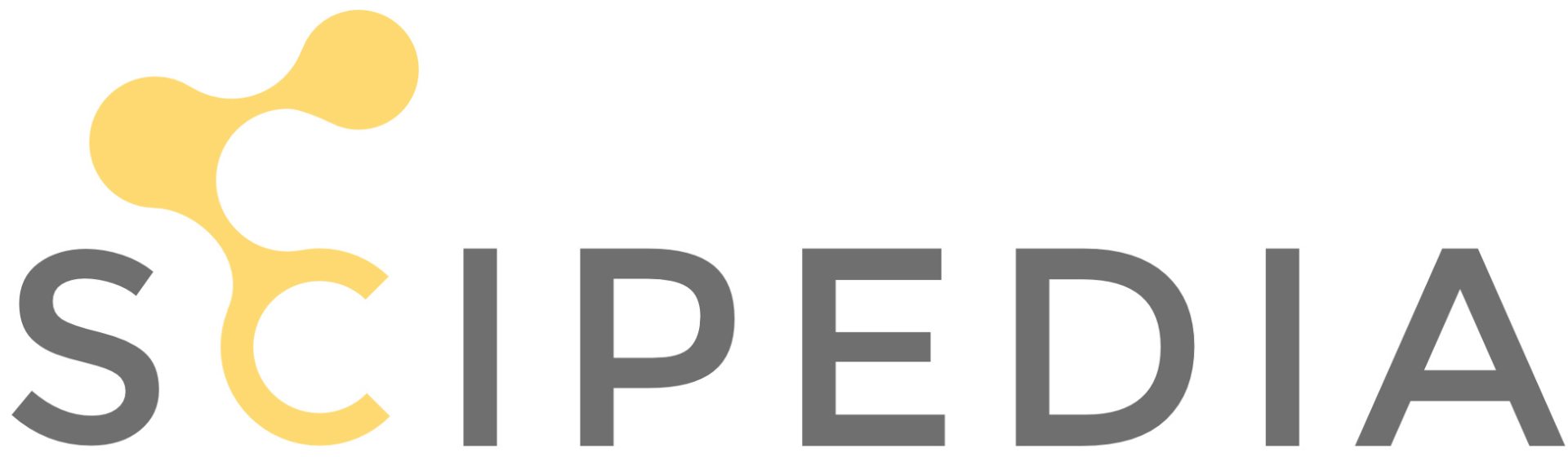

Register for free at https//www.scipedia.com to download the version without the watermark 